\title{
Dioxoiodane Compounds as Versatile Sources for lodine(I) Chemistry
}

\author{
Kilian Muñiz, ${ }^{*[a, b]}$ Belén García, ${ }^{[a]}$ Claudio Martínez ${ }^{[a]}$ and Alessandro Piccinelli ${ }^{[a]}$
}

\begin{abstract}
The general synthesis, isolation and characterization of electrophilic iodine reagents of the general formula $\mathrm{R}_{4} \mathrm{~N}\left[\mathrm{l}\left(\mathrm{O}_{2} \mathrm{CAr}\right)_{2}\right]$ is reported. These compounds are air- and moisture-stable iodine(I) reagents, which were characterized including X-ray analysis. They represent conceptually new iodine $(I)$ reagents with anions as stabilizers. These compounds display the expected performance as electrophilic reagents upon interaction with electron-rich substrates. The performance of these compounds in a total of 47 different reactions of vicinal iodooxygenation of alkenes is studied and some key features on the reagents are revealed.
\end{abstract}

\section{Introduction}

Oxidative functionalization of hydrocarbons with iodine reagents has recently attracted a significant amount of attention..$^{[1,2]}$ In general, this iodine-based methodology benefits from the absence of any transition metals and meets with the requirements of benign synthesis that have been proposed as a key aspect for modern transformations. Defined electrophilic iodine catalysis has been at the centre of recent development. ${ }^{[3,4]}$ Molecular iodine itself is a polarizable molecule that has found wide application as a pro-electrophile. ${ }^{[1,2]}$ Common electrophilic iodinating reagents mostly rely on preformed $\mathrm{N}$-iodo amides such as $\mathrm{N}$ iodosuccinimide (NIS). ${ }^{[5]}$ Apart from such $\mathrm{N}$-iodinated reagents, stabilized halonium reagents have been at the centre of attention and have found widespread application in organic synthesis. These reagents represent an umpolung version of the common nucleophilic iodine and thus allow for a series of iodinating reactions that are not accessible by classic means. ${ }^{[6]}$

A major accomplishment in the area rests with the recognition by Barluenga that stabilization of the iodonium atom can be accomplished by pyridine moieties. ${ }^{[7-10]}$ The resulting complex was prepared in form of the corresponding tetrafluoroborate salt and represents a stable reagent for convenient iodination of organic molecules. Among the prominent reaction pathways that were uncovered for this reagent, iodooxygenation of alkenes was among the first that were investigated. ${ }^{[7]}$

[a] Prof. Dr. K. Muñiz, B. García, Dr. C. Martínez, A. Pccinelli Institute of Chemical Research of Catalonia (ICIQ), The Barcelona Institute of Science and Technology, Av. Països Catalans 16, 43007 Tarragona, Spain

E-mail: kmuniz@iciq.es

[b] Prof. Dr. K. Muñiz

ICREA,

Pg. Lluís Companys 23, 08010 Barcelona, Spain

Supporting information for this article is given via a link at the end of the document.
Alternatively, electrochemical oxidation can provide an elegant approach to generate iodine cations in solution, providing that the solvent exercises as stabilizing ligand. Yoshida has pursued this approach and has demonstrated that dimethylsulfoxide as solvent promotes the formation of solvated iodonium derivatives, which promote vicinal difunctionalization of alkenes, allenes and butadienes. $^{[11]}$

lodine(l) reagents:

stabilization with neutral ligands
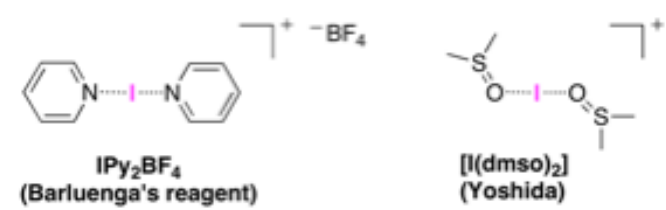

lodine(I) reagents:

stabilization with neutral ligands



Figure 1. Stable iodine(I) compounds.

These compounds are characterized by the stabilization of cationic iodine cores with neutral ligands. An alternative would be the linear coordination of two anionic ligands to provide an overall monoanionic complex. We have recently reported the synthesis of such a new stable iodine(I) compound, which represents the tetrabutylammonium derivative of the catalyst resting state in an iodine catalyzed Hofmann-Löffler reaction. ${ }^{[12]}$ Obviously, in this type of $\mathrm{C}-\mathrm{H}$ amination reaction the specific reactivity of the electrophilic iodine $(\mathrm{I})$ reagent gives rise to an $\mathrm{N}$-iodination, which is the origin of the required radical-based reactivity.

We speculated that in addition the isolated iodine(I) reagent should be able to display typical reactivity of electrophilic halide derivatives. We here provide the full account on the accessibility of electrophilic iodine reagents of the general formula $\mathrm{R}_{4} \mathrm{~N}\left[\mathrm{I}\left(\mathrm{O}_{2} \mathrm{CAr}\right)_{2}\right]$ and their reactivity towards alkenes within a vicinal iodooxygenation reaction. ${ }^{[13,14,15]}$

\section{Results and Discussion}

Reagent synthesis, structure, solution behavior. The synthesis of dioxoiodanes is general for a number of different benzoates as ligands. It follows the general synthetic outline from Scheme 1 and is based on an effective comproportionation reaction that originates from the reaction between an ammonium 
iodide 1 and a hypervalent iodine(III) reagent $2 .{ }^{[16]}$ Compounds 3 are isolated as white to yellow solids that display reasonable stability against air and moisture.

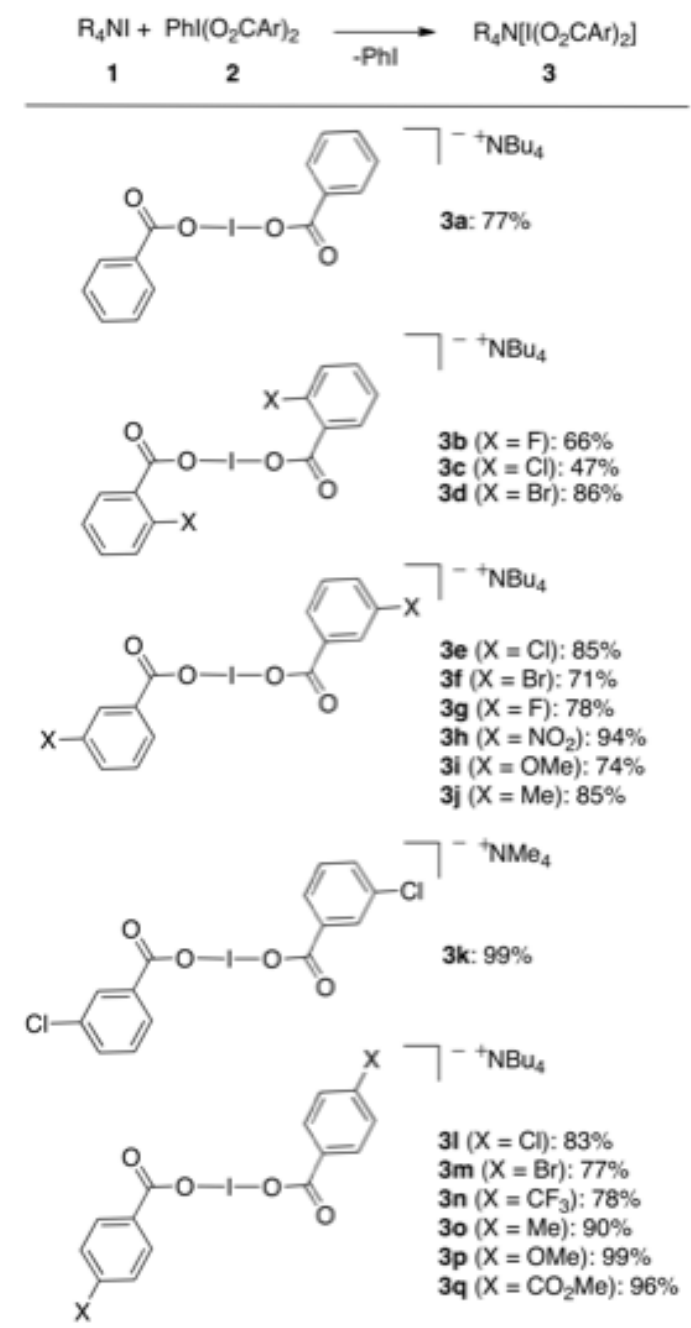

Scheme 1. Synthesis of iodine(I) reagents of the general formula $\mathrm{R}_{4} \mathrm{~N}\left[\mathrm{I}\left(\mathrm{O}_{2} \mathrm{CAr}\right)_{2}\right]$

Four of the new compounds were submitted to further analysis by $\mathrm{X}$-ray diffraction of single crystals. The corresponding structures of compounds $\mathbf{3 f}, \mathbf{3 g}, \mathbf{3} \mathbf{i}$ and $\mathbf{3 k}$ are depicted in Figure $2^{[17]}$ and compliment the one of compound $3 e$ reported earlier. ${ }^{[12]}$ The key features of these compounds are (i) the expected linear coordination mode of the anionic carboxylates at the central iodine atom and (ii) the rather short iodine-oxygen bond distances in the range of 2.16 to $2.20 \AA$. This demonstrates a shorter bonding and thus stronger interaction for the anionic ligands than in comparable pyridine $(2.255-2.261 \AA)^{[18,19,20]}$ and dmso adducts $(2.27 \AA)^{[11]}$
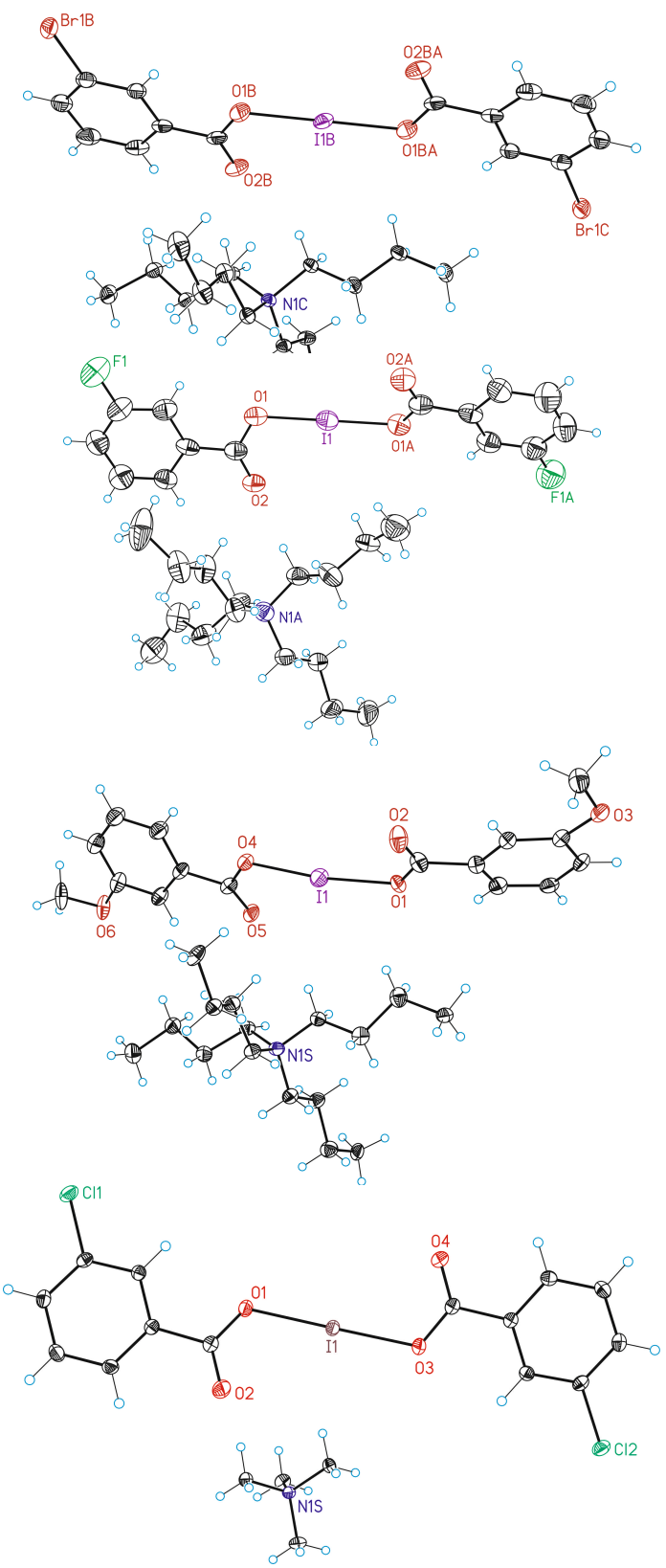

Figure 2. Solid state structures of compounds $\mathbf{3 f}, \mathbf{3 g}, \mathbf{3 i}$ and $\mathbf{3 k}$ (ORTEP plots at $50 \%$ probability). Selected bond lengths $(\AA)$ and angles $\left({ }^{\circ}\right)$. 3f: I1A-O1A\#1 2.1835(18), I1A-O1A 2.1836(18), O1A-I1A-O1A\#1 180. 3g: I1-01 2.193(5), O1I1-O1' 179.8(2). 3i: I1-O1 2.177(8), I1-O4 2.162(8), O4-I1-O1 168.7(7). 3k: I1O1 2.1962(10), I1-O3 2.2021(11), O1-I1-O3 176.62(4).

lodine reagents 3 display a remarkable stability in solution. A control experiment with a solution of the two fluorinated compounds $\mathbf{3} \mathbf{b}$ and $\mathbf{3} \mathbf{g}$ displayed no anion scrambling according to monitoring by ${ }^{19} \mathrm{~F}$ NMR confirming that the two anionic iodine units remained stable under neutral conditions (Scheme 2). ${ }^{[21]}$ 


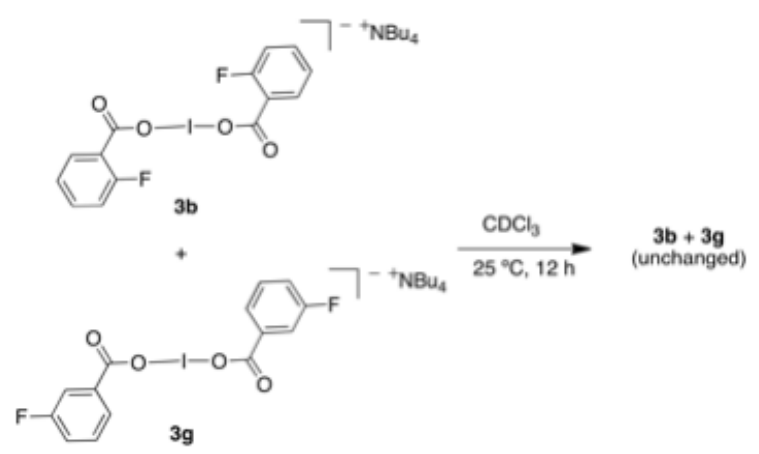

Scheme 2. Experiment on solution stability of iodine(I) compounds 3.

Reagent performance in alkene oxidation. The behavior of compounds 3 towards styrenes was investigated. Based on the known propensity of iodine(I) reagents to induce iodooxygenation reactions, this particular reaction was employed for an exploration in the present case (Scheme 3). As observed for the complete set of 16 examples, all reagents 3 provided the corresponding 1,2difunctionalized products in $60-93 \%$ isolated yield. The best yield was obtained with the 3 -chlorobenzoate derivative $\mathbf{3 e}$. It is noteworthy that products $\mathbf{5}$ display pronounced stability regarding the carbon-iodine bond. For example, no undesired derivatization as could for example result from Woodward pathway ${ }^{[22]}$ was observed in any of the cases.

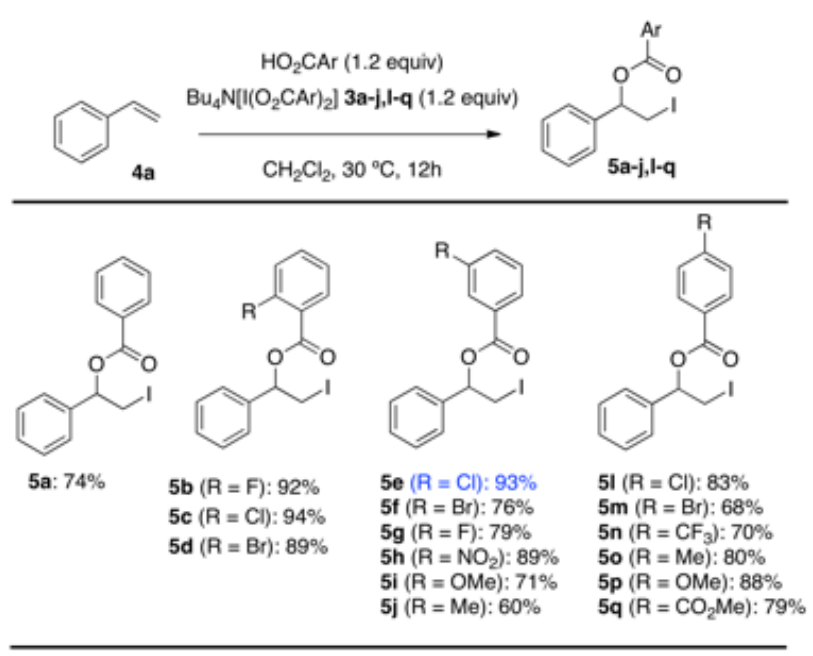

Scheme 3. lodooxygenation of styrene $4 a$ with the set of reagents 3 .

For the reactions from Scheme 3, the reagents 3 were activated by addition of an equimolar amount of free carboxylic acid, which greatly accelerates the reaction. While reagents 3 are reactive by themselves, the corresponding reactions are comparably slow. The observed acceleration by free acid has been invoked to be the result of a transformation of the ammonium salts $\mathbf{3}$ into the free acids, which readily give rise to the active reagent $1-\mathrm{O}_{2} \mathrm{CAr}$ (Scheme 4). It is important to note that activation with a different acid is possible, but leads to formation of product mixtures due to anion scrambling. This context was clarified for representative reactions of $3 n$ and $3 p$ and activation with benzoic acid, which provided 4:1-product mixtures of $5 \mathrm{n}$ and $5 \mathrm{a}$ and 59 and $5 \mathrm{a}$, respectively, regardless of the electronic substitution, since the donor substituent in $\mathbf{3 n}$ leads to an identical outcome as in case of the acceptor substituent in $3 p$.
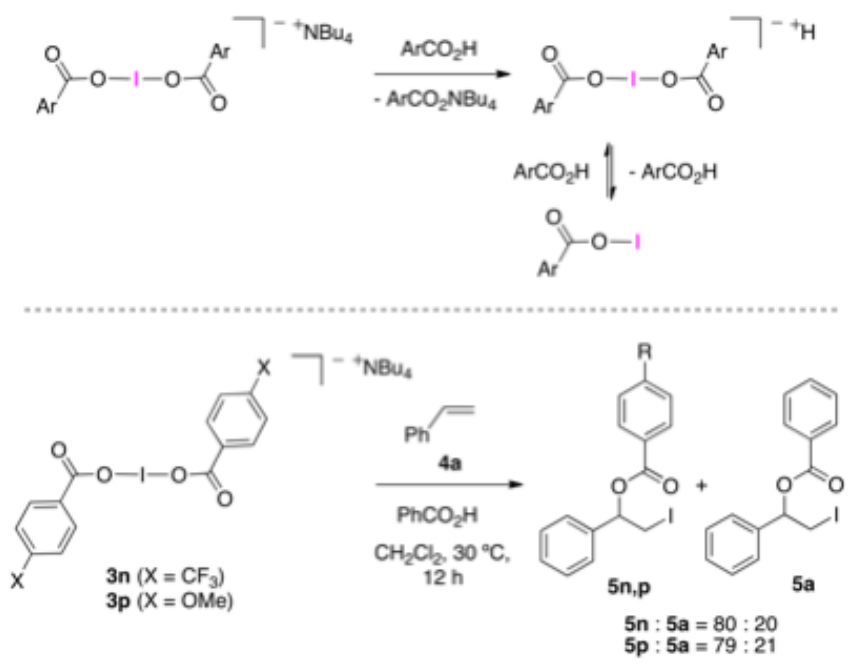

Scheme 4. Experiment on the role of acid activation in the iodooxygenation of styrene $\mathbf{4 a}$.

Despite the uniform high yields observed in the vicinal difunctionalization from Scheme 3, it remained of interest to study potential substitution effects on the initial rate of iodooxygenation. As represented in Figure 3, such electronic influences are indeed present in oxidation of styrene $\mathbf{4 a}$ with different iodine $(\mathrm{I})$ reagents. To avoid any potential steric influence on the reaction rate, the 4substituted benzoic acid derivatives $\mathbf{3 n}-\mathbf{q}$ were compared to reagent $3 a$ with benzoic acids as ligands to iodine. As can be observed from the relative rates, electron-attracting substitution enhances the initial rate of the reaction. This is in agreement with the qualitative expectation that less stabilized carboxylate ligands in 3 will lead to a more rapid liberation of the active reagent I$\mathrm{O}_{2} \mathrm{CAr}$, which in addition will be of more pronounced electrophilic character.

The corresponding Hammett plot supports this analysis. Based on the initial rates of the individual reactions, a linear relationship is obtained between the logarithm of the rate fractions versus the Hammett $\sigma$ values (Figure 3, bottom). The graphical correlation yields a corresponding $\rho$ value of 0.78 , which is indicative of a build up of electrophilicity in the slow step of the reaction as discussed before. 


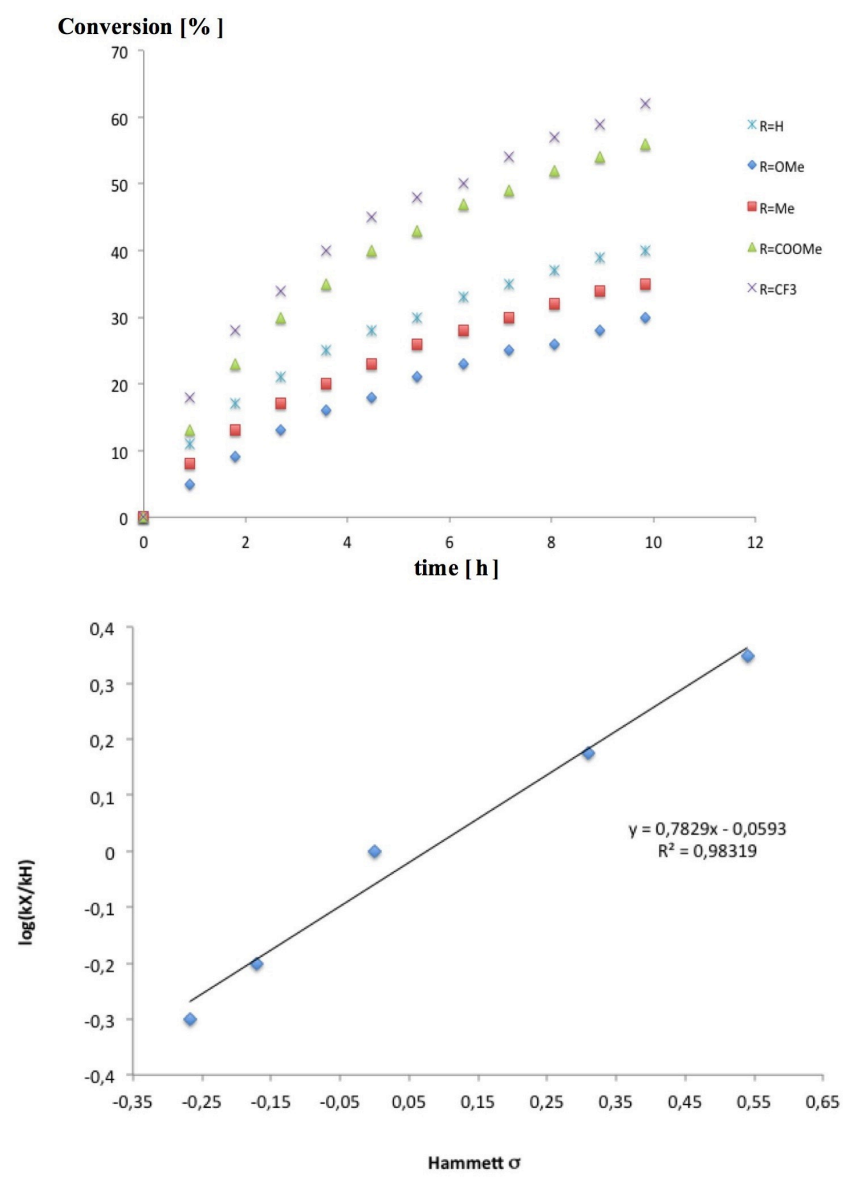

Figure 3. Effect of the 4-substitution on the initial rate of the iodooxygenation of styrene 4a with different iodine reagents (top) and Hammett correlation (bottom).

Since in the investigation from Scheme 3 the highest yield in styrene iodooxygenation was obtained with compound $\mathbf{3 e}$, further studies regarding the general scope of iodooxygenation reactions were conducted using this reagent. As demonstrated in Scheme 5 for 17 examples, the corresponding vicinal difunctionalization reactions proceed for a series of different substitution patterns at the arene core, which includes individual 2-, 3- and 4-substitution as in products $6 \mathbf{b}-\mathbf{0}$ and in higher-substituted derivatives $6 \mathrm{p}-\mathrm{r}$. The same substrate tolerance is observed for $\alpha$-substituted styrenes $\mathbf{7 a - g}$, which give rise to the corresponding products $\mathbf{8 a}$ g in $55-98 \%$ isolated yield. As in the case of the previous examples, all reactions proceed with complete regio- and chemoselectivity in favor of the iodine incorporation at the terminal position. This observation is consistent with the general expectation of a mechanism that involves an iodonium intermediate resulting from alkene addition to the electrophilic iodine center in reagents 3 followed by nucleophilic benzoate opening at the benzylic position.

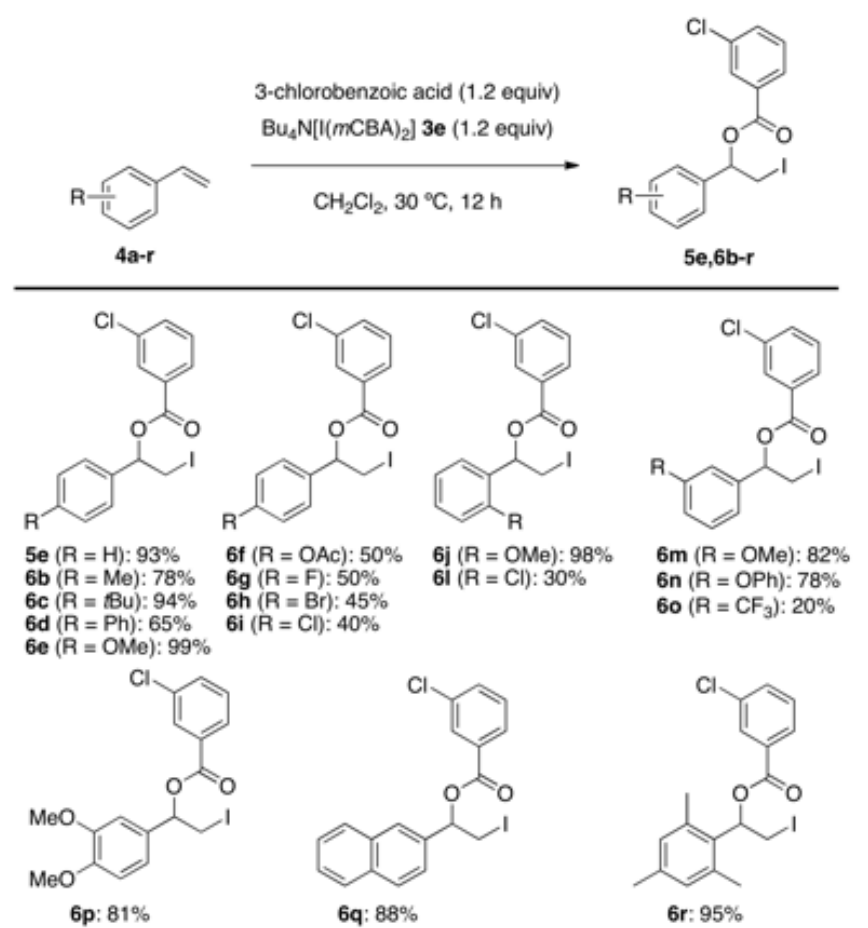

Scheme 5. lodooxygenation of styrenes $4 a-r$ with reagent $3 e$.

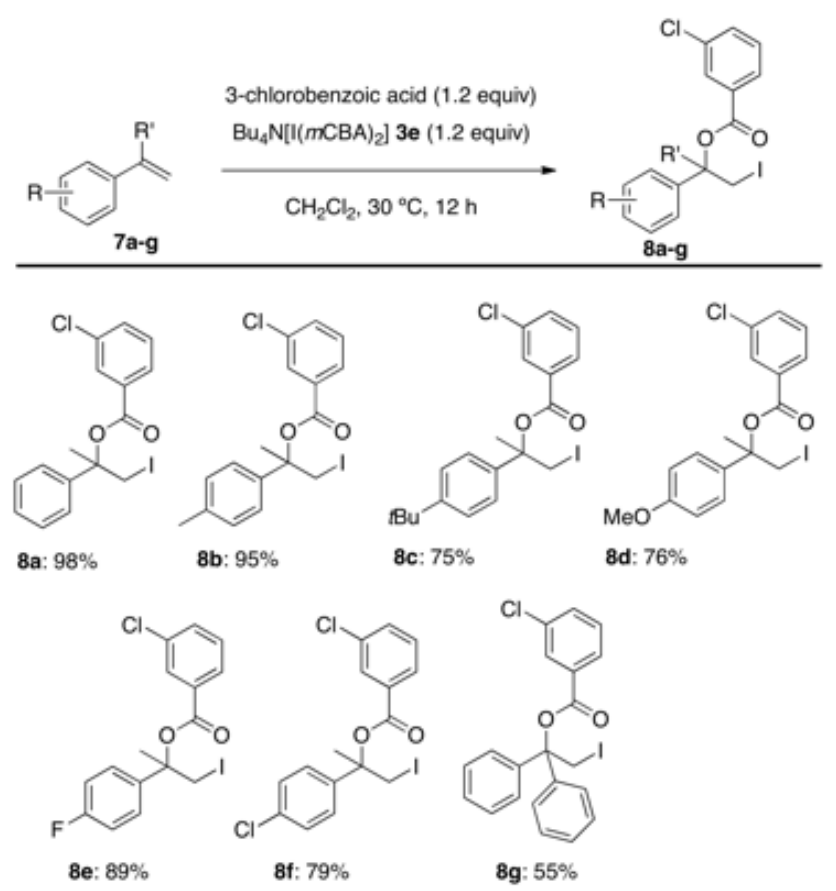

Scheme 6. lodooxygenation of $\alpha$-substituted styrenes 7a-g with reagent $3 \mathbf{e}$.

It is noteworthy that these vicinal iodooxygenation reactions proceed with stereospecificity regarding the geometry of internal double bonds. This was demonstrated for $(Z)$ - and $(E)-\beta$-methyl styrenes $9 \mathbf{a}$ and $\mathbf{b}$. While the latter one provided a single stereoisomeric product $\mathbf{1 0 b}$, the former one yielded the opposite 
isomer $10 \mathrm{a}$, together with a minor amount of isomerization (Scheme 7). This result compares well with the outcome for the related cationic $\mathrm{I}(\mathrm{dmso})_{2}$ reagent. $^{[11 \mathrm{a}]}$ Cyclic alkenes such as $9 \mathrm{c}$ and $9 \mathrm{~d}$ also give the corresponding regioselective products $10 \mathrm{c}$ and $10 \mathrm{~d}$ with the expected stereoselectivity.

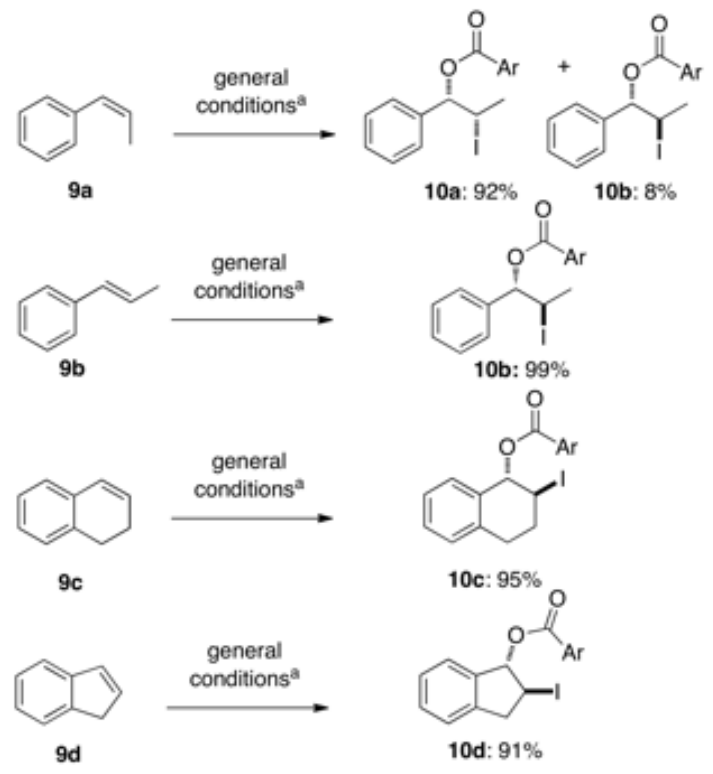

Scheme 7. lodooxygenation of internal alkenes 9 a-d with reagent $3 \mathbf{e}{ }^{a}$ General conditions: 3 -chlorobenzoic acid (1.2 equiv), 3e (1.2 equiv), $\mathrm{CH}_{2} \mathrm{Cl}_{2}, 25^{\circ} \mathrm{C}, 12$ h. $\mathrm{Ar}=3-\mathrm{Cl}-\mathrm{C}_{6} \mathrm{H}_{4}$

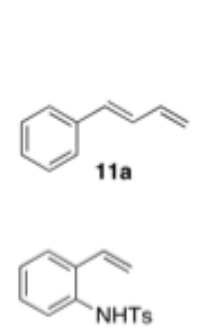

$4 \mathrm{~s}$

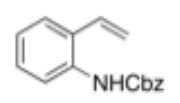

$4 \mathrm{t}$

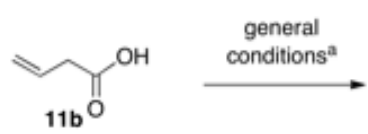

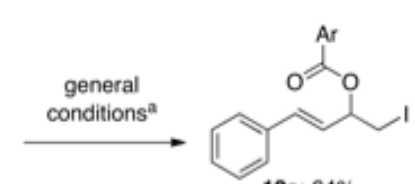

12a: $64 \%$<smiles>CN1CC(OC(=O)Br)c2ccccc21</smiles>

12b: $61 \%$<smiles>O=C(O)Nc1ccccc1C(CI)OC(=O)O</smiles>

6s: $84 \%$<smiles>C=CCOC(=O)OCC(=O)O</smiles>

Scheme 8. Further examples on oxidation of alkenes $4 \mathbf{s , t , 1 1 a , b}$ with reagent 3e. ${ }^{a}$ General conditions: 3 -chlorobenzoic acid (1.2 equiv), 3e (1.2 equiv), $\mathrm{CH}_{2} \mathrm{Cl}_{2}, 25^{\circ} \mathrm{C}, 12$ h. $\mathrm{Ar}=3-\mathrm{Cl}-\mathrm{C}_{6} \mathrm{H}_{4}$

Further reactivity was explored for additional substrates such as the 1,3-butadiene 11a (Scheme 8). As expected from a related diamination with hypervalent iodine reagents, ${ }^{[23]}$ the reaction with 3e led to the formation of a single regioisomeric product $\mathbf{1 2 a}$, which is the thermodynamically preferred product due to maintenance of the styrene conjugation. 2-Aminostyrene also constitutes an interesting substrate. While its Cbz-protected derivative $4 \mathrm{t}$ behaves as the styrene derivatives from Scheme 5 and thus undergoes clean iodooxygenation to $\mathbf{5 s}$, the corresponding tosylamide $4 \mathrm{~s}$ promotes an aminooxygenation to the 3-oxygenated indoline 12b. Interestingly, this product proofed to be stable against indole formation ${ }^{[24]}$ via elimination. A related cyclization was attempted with 11c as precursor to iodolactonization. ${ }^{[25]}$ However, the allyl ester $12 \mathrm{c}^{[26]}$ was formed as the only product, which is believed to result from an acid exchange between $3 \mathrm{e}$ and $11 \mathrm{c}$ to provide the iodine $(\mathrm{I})$ derivative of $11 \mathrm{c}$, which undergoes iodine-promoted decarboxylation ${ }^{[27]}$ followed by oxygenation to the allylic product.

Hayashi (2015)
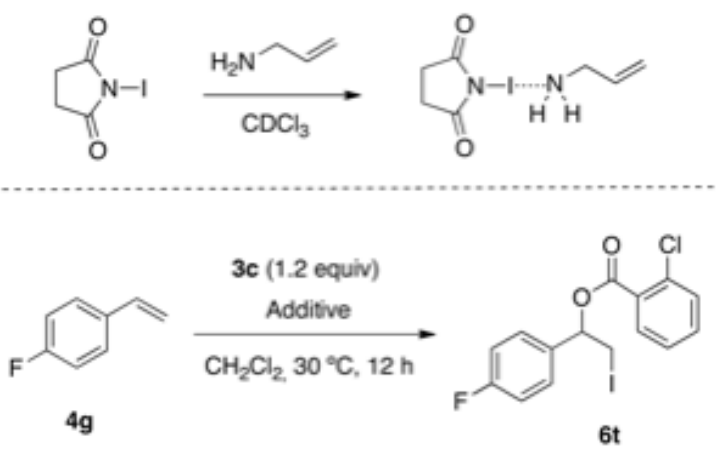

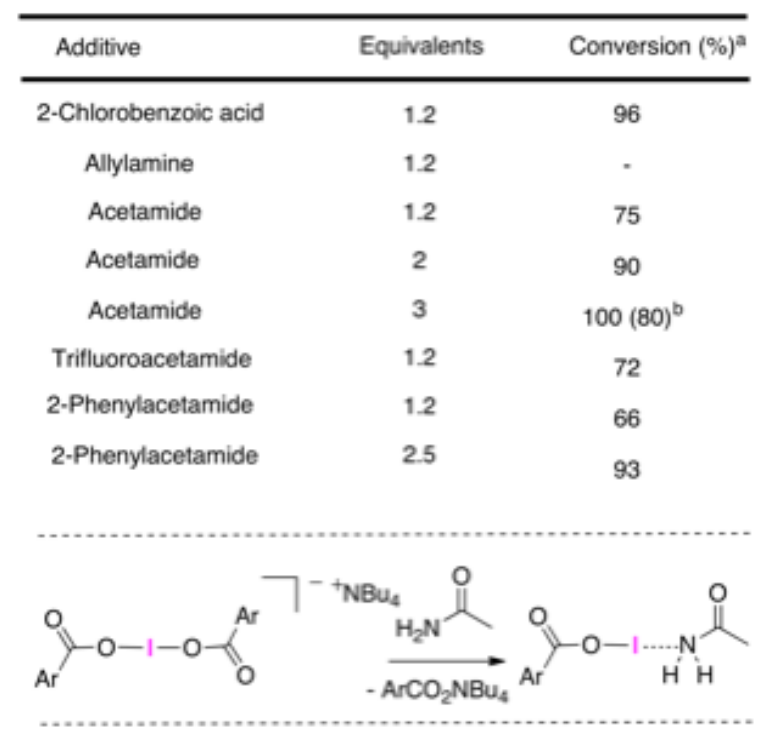

Scheme 9. lodooxygenation upon activation of reagent $3 c$ with amides. ${ }^{a}$ Conversion by ${ }^{19} \mathrm{~F}$ NMR with fluorobenzene as internal standard. ${ }^{\mathrm{b}}$ Isolated yield after purification.

Finally, a recent report by Hayashi on the possible activation of $N$ iodosuccinimide with amine groups (Scheme 9$)^{[28]}$ prompted the investigation on related reactivity in the present system. While allylamine turned out to be incompatible with iodine $(I)$ reagent $3 c$, related acetamides promoted the iodooxygenation of 4- 
fluorostyrene $\mathbf{4 g}$ to the corresponding product $\mathbf{6 t}$ in a way that is comparable to activation with 2-chlorobenzoic acid. Although due to instability in solution, no structural data has become available yet, an activation of the iodine(I) by acetamide similar to the case of Hayashi is proposed to be involved in this case.

This outcome demonstrates that there are further possible activation modes for compounds $\mathbf{3}$ in metal-free oxidation reactions. Exploration of such pathways as well as the combination of reagents 3 as oxidants in transition metal mediated and catalyzed transformations are currently under progress.

\section{Conclusions}

We have presented the general synthesis of isolable, air-stable electrophilic iodine $(\mathrm{I})$ reagents, which are stabilized by coordination of two carboxylate units. Their structures and solution behavior have been discussed in detail. These compounds add to an existing number of stable iodine(I) precursors as sources for electrophilic reagents. Their versatile applicability to organic synthesis has been demonstrated by a number of chemo- and regioselective iodooxygenation reactions of styrenes. Their synthetic potential remains yet to be fully explored, and there are reasons to expect that the new compounds will be able to make future impact.

\section{Experimental Section}

General procedure for the synthesis of iodine derivatives 3: The synthesis was adapted from a recently published procedure. ${ }^{[12]}$ A Schlenk tube equipped with a stirrer bar was charged with the corresponding iodine(III) compound (1.0 equiv), the ammonium iodide $(2.17 \mathrm{mmol}, 1.0$ equiv), evacuated and backfilled with argon. At this point, $4 \mathrm{~mL}$ of $\mathrm{CDCl}_{3}$ were added. The solution was stirred at $25^{\circ} \mathrm{C}$ for $12 \mathrm{~h}$. $\mathrm{Et}_{2} \mathrm{O}$ was then added to induce precipitation of a solid, which was filtered and washed with $\mathrm{Et}_{2} \mathrm{O}$. The compound was dried under reduced pressure to obtain the pure title compound.

General procedure for the difunctionalization reaction of alkenes. A Schlenk tube equipped with a stirrer bar was charged with 3-chlorobenzoic acid (1.2 equiv), tetrabutylammonium bis((3-chlorobenzoyl)oxy)iodate(I) (1.2 equiv) and ( $3 \mathrm{~mL})$ of dry dichloromethane. The corresponding styrene ( $0.2 \mathrm{mmol}, 1$ equiv) was added and the reaction was stirred overnight at $30{ }^{\circ} \mathrm{C}$. Then $\mathrm{DCM}$ was added and the solution was washed with a saturated aqueous solution of $\mathrm{Na}_{2} \mathrm{~S}_{2} \mathrm{O}_{3}$. The organic phase was dried over $\mathrm{Na}_{2} \mathrm{SO}_{4}$, filtered and the solvents were removed under reduced pressure. The crude product was purified by flash column chromatography (hexane/EtOAc, 9:1) to provide the corresponding iodooxygenated products.

\section{Acknowledgements}

Financial support for this project was provided from the Spanish Ministry for Economy and Competitiveness and FEDER (CTQ2014-56474R grant to K. M., and Severo Ochoa Excellence Accreditation 2014-2018 to ICIQ, SEV-2013-0319) and Cellex-
ICIQ Program (fellowship to C. M.). The authors are grateful to $E$. Escudero-Adán for support with the X-ray analyses.

Keywords: Alkenes • lodine $•$ Difunctionalization $•$ Synthetic Methods $\cdot$ Oxidation

[1] lodine Chemistry and Applications (Ed.: T. Kaiho), Wiley, New Jersey 2015

[2] F. C. Küpper, M. C. Feiters, B. Olofsson, T. Kaiho, S. Yanagida, M. B. Zimmermann, L. J. Carpenter, G. W. Luther III, Z. Lu, M. Jonsson, L. Kloo, Angew. Chem. Int. Ed. 2011, 123, 11802.

[3] Leading reviews: a) P. Finkbeiner, B. J. Nachtsheim, Synthesis 2013 45, 977-999; b) D. Liu, A. Lei, Chem. Asian J. 2015, 10, 806; c) M. Uyanik, K. Ishihara ChemCatChem 2012, 4, 177-185; d) M. S. Yusubov, V. V Zhdankin, Reef. Tech. 2015, 1, 49.

[4] For some impressive enantioselective reactions: a) M. Uyanik, $\mathrm{H}$ Okamoto, T. Yasui,, K. Ishihara, Science 2010, 328, 1376; b) M. Uyanik, H. Hayashi, K. Ishihara, Science 2014, 345, 291; c) B. J. Nachtsheim Science 2014, 345, 270; d) M. Uyanik, D. Suzuki, T. Yasui, K. Ishihara, Angew. Chem. Int. Ed. 2011, 50, 5331

[5] I. V. Koval', Russ. J. Org. Chem. 2002, 38, 301.

[6] A. H. Neilson, (Ed.) Organic Bromine and lodine Compounds. In The Handbook of Environmental Chemistry Part 3R; Springer: Berlin, Heidelberg, 2003

[7] J. Barluenga, J. M. González, P. J. Campos, G. Asensio, Angew. Chem. Int. Ed. 1985, 24, 319

[8] J. Barluenga, Pure Appl. Chem. 1999, 71, 431.

[9] M. Justin, L. Amber, G. Benjamin, Org. Synth. 2010, 87, 288.

[10] a) J. Barluenga, F. González-Bobes, M. C. Murguía, S. R. Ananthoju, J. M. González, Chem. Eur. J. 2004, 10, 4206. b) G. Espuña, S. R. Ananthoju, D. Andreu, J. Barluenga, X. Pérez, A. Planas, G. Arsequell, G. Valencia, Biochem. 2006, 45, 5957; c) J. Barluenga, J. M. González, M. A. García-Martín, P. J. Campos, G. Asensio, J. Org. Chem. 1993, 58 2058; d) J. Barluenga, E. Campos-Gómez, A. Minatti, D. Rodríguez, J. M. González, Chem. Eur. J. 2009, 15, 8946; e) J. Barluenga, H. Vázquez-Villa, I. Merino, A. Ballesteros, J. M. González, Chem. Eur. J. 2006, 12, 5790; f) J. Barluenga, H. Vázquez-Villa, A. Ballesteros, J. M González, Adv. Synth. Catal. 2005, 347, 526; g) J. Barluenga, M. Trincado, M. Marco-Arias, A. Ballesteros, E. Rubio, J. M. González, Chem. Commun. 2005, 2008; h) J. Barluenga, M. Trincado, E. Rubio, J. M. González, Angew. Chem. Int. Ed. 2006, 45, 3140

[11] a) Y. Ashikari, A. Shimizu, T. Nokami, J.-i. Yoshida, J. Am. Chem. Soc. 2013, 135, 16070; b) A. Shimizu, R. Hayashi, Y. Ashikan, T. Nokami, J.i. Yoshida, Beilstein J. Org. Chem. 2015, 11, 242.

[12] C. Martínez, K. Muñiz, Angew. Chem. Int. Ed. 2015, 54, 8287.

[13] Recent selected examples: a) D. S. Rao, T. R. Reddy, K. Babachary, S. Kashyap, Org. Biomol. Chem. 2016, 14, 7529; b) M. K. Agrawal, S. Adimurthy, B. Ganguly, P. K. Ghosh, Tetrahedron. 2009, 65, 2791; c) W. Wei, X. Liu, D. Yang, R. Dong, Y. Cui, F. Yuan, H. Wang, Tetrahedron Lett. 2015, 56, 1808; d) M. Alikarami, M. Farhadi, Helv. Chim. Acta. 2015, 98, 1302; e) R. S. Ribeiro, P. M. Esteves, M. C. S. Mattos, Tetrahedron Lett. 2007. 48, 8747; f) M. Alikarami, M. Farhadi, Helv. Chim. Acta. 2015, 98, 1302.

[14] For recent examples on the combination between $I_{2}$ and hypervalent iodine: a) A. Kirschning, M. S. Yusubov, R. Y. Yusubova, J. Y. Park, K.W. Chi, Beilstein J. Org. Chem. 2007, 3, 19; b) M. S. Yusubov, R. Y. Yusubova, A. Kirschning, J. Y. Park, K.-W. Chi, Tetrahedron Lett. 2008, 49, 1506; c) M. S. Yusubov, R. Y. Yusubova, T. V. Funk, K.-W. Chi, A. Kirschning, V. V. Zhdankin, Synthesis 2010, 3681; d) H. Gottam, T. K. Vinod, J. Org. Chem. 2011, 76, 974; e) M. S. Yusubov, R. Y. Yusubova, V. N. Nemykin, A. V. Maskaev, M. R. Geraskina, A. Kirschning, V. V. Zhdankin, Eur. J. Org. Chem. 2012, 5935; f) J.-H. Ye, Z. Hu, Y. Wang, W. Zhang, Y. Zhang Tetrahedron Lett. 2012, 53, 6858; g) D. L. Priebbenow, R. W. Gable, J. Baell J. Org. Chem. 2015, 80, 4412; h) J. K. Vandavasi, W. P. Hu, G. C. Senadi, H.-T. Chen, H.-Y. Chen, K.-C. 
Hsieh, J.-J. Wang, Adv. Synth. Catal. 2015, 357, 2788; i) J. Barluenga, F. González-Bobes, J. M. González, Angew. Chem. int. Ed. 2002, 41 2556.

[15] For classical work in the area: a) R. Hernández, A. Rivera, J. A. Salazar, E. Suárez, Chem. Commun. 1980, 958; b) C. Betancor, J. I. Concepción, R. Hernández, J. A. Salazar, E. Suárez, J. Org. Chem. 1983, 48, 4430; c) P. De Armas, R. Carrau, J. L. Concepción, C. G. Francisco, R. Hernández, E. Suárez, Tetrahedron Lett. 1985, 26, 2493; d) R. Carrau, R. Hernández, E. Suárez, C. Betancor, Perkin Trans. / 1987, 937; e) P. De Armas, C. G. Francisco, R. Hernández, J. A. Salazar, E. Suárez, Perkin Trans. I 1988, 3255; f) R. Fan, D. Pu, F. Wen, J. Wu, J. Org Chem. 2007, 72, 8994.

[16] R. Giri, J.-Q. Yu, e-EROS Encyclopedia of Reagents for Organic Synthesis, DOI: 10.1002/047084289X.rn00915 (2008).

[17] X-ray crystallographic data for compounds $\mathbf{3 f}, \mathbf{3 g}, \mathbf{3 i}$ and $\mathbf{3 k}$ have been deposited with the Cambridge Crystallographic Data Centre database (http://www.ccdc.cam.ac.uk/) under codes CCDC 1496317 (3f), 1496318 (3g), 1496319 (3i) and 1496320 (3k), respectively.

[18] C. Álvarez-Rúa, S. García-Granda, A. Ballesteros, F. González-Bobes, J. M. González, Acta Cryst. 2002, E58, 01381.

[19] Recent structural work: a) A. C. C. Carlsson, K. Mehmeti, M. Uhrbom, A. Karim, M. Bedin, R. Puttreddy, R. Kleinmeier, A. A. Neverov, B Nekoueishahraki, J. Grafensetin, K. Rissanen, M. Erdelyi, J. Am. Chem. Soc. DOI: 10.1021/jacs.6b03842; b) M. Bedin, A. Karim, M. Reitti, A.-C
C. Carlsson, F. Tepic, M. Cetina, F. Pan, V. Havel, F. Al-Ameri, V. Sindelar, K. Rissanen, J. Gräfenstein, M. Erdélyi, Chem. Sci. 2015, 6, 3746; c) Y. Kim, E. J. Mckinley, K. E. Christensen, N. H. Rees, A. L. Thompson, Cryst. Growth Des. 2014, 14, 6294.

[20] R. W: Troff, T. Mäkelä, F. Topic, A. Valkonen, K. Raatikainen, K. Rissanen, Eur. J. Org. Chem. 2013, 1617.

[21] See Supporting Information for details.

[22] R. B. Woodward, F. V. Brutcher, Jr., J. Am. Chem. Soc. 1958, 80, 209.

[23] A. Lishchynskyi, K. Muñiz, Chem. Eur. J. 2012, 18, 2213.

[24] L. Fra, A. Millán, J. A. Souto, K. Muñiz, Angew. Chem. Int. Ed. 2014, 53, 7349.

[25] a) M. S. Oderinde, H. N. Hunter, S. W. Bremner, M. G. Organ, Eur. J. Org. Chem. 2012, 175; b) M. D. Dowle, D. L. Davies, Chem. Soc. Rev. 1979, 8, 171; c) E. J. Corey, N. M. Weinshenker, T. K. Schaaf, W. Huber, J. Am. Chem. Soc. 1969, 91, 5675

[26] K. Kiyokawa, S. Yahata, T. Kojima, S. Minakata, Org. Lett. 2014, 16 , 4646 .

[27] T. A. Strayer, C. C. Culy, M. H. Bunner, A. R. Frank, P. A. Albiniak, Tetrahedron Lett. 2015, 56, 6807.

[28] J. Li, M. J. Lear, Y. Hayashi, Angew. Chem. Int. Ed. 2015, 54, 12986. 
Entry for the Table of Contents (Please choose one layout)

Layout 2:

\section{FULL PAPER}

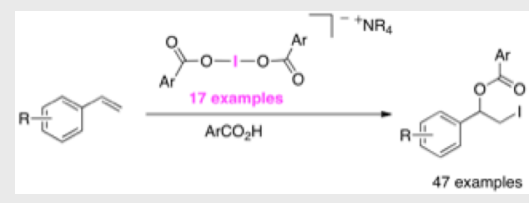

Stable and readily applicable for oxidation. A family of new iodine(I) derivatives is presented, which enables a number of alkene difunctionalization reactions under convenient conditions.
Kilian Muñiz, * Belén García, Claudio Martínez, Alessandro Piccinelli.

Page No. - Page No.

Dioxoiodane Compounds as Versatile Sources for lodine(I) Chemistry 